\title{
General Psychiatry Nutritional and herbal supplements in the treatment of obsessive compulsive disorder
}

\author{
Canan Kuygun Karcı (D) , ${ }^{1}$ Gonca Gül Celik ${ }^{2}$
}

To cite: Kuygun Karcı C, Gül Celik G. Nutritional and herbal supplements in the treatment of obsessive compulsive disorder. General Psychiatry 2020;33:e100159. doi:10.1136/ gpsych-2019-100159

Received 03 October 2019 Revised 02 December 2019 Accepted 19 December 2019

Check for updates

(c) Author(s) (or their employer(s)) 2020. Re-use permitted under CC BY-NC. No commercial re-use. See rights and permissions. Published by BMJ.

${ }^{1}$ Child and Adolescent Psychiatry, Dr. Ekrem Tok Psychiatry Hospital, Adana, Turkey

${ }^{2}$ Child and Adolescent

Psychiatry, Cukurova University Medical Faculty, Adana, Turkey

Correspondence to Dr Canan Kuygun Karcl; c_kuy@hotmail.com

\section{ABSTRACT}

Obsessive-compulsive disorder (OCD) is a neuropsychiatric disorder that is characterised by obsessions and compulsions. The recommended treatments for OCD are cognitive- behavioural therapy using exposure and response prevention and/or pharmacotherapy. On the other hand, some nutritional and herbal supplements may be effective in the treatment of OCD. Nutritional and herbal supplements in OCD treatment will be reviewed in this paper. PubMed (Medline), Cochrane Library and Google Scholar databases were reviewed for the topic. There are some supplements that have been researched in OCD treatment studies such as vitamin $\mathrm{D}$, vitamin $\mathrm{B}_{12}$, folic acid, homocysteine, trace elements, $\mathrm{N}$-acetyl cysteine, glycine, myoinositol, St John's wort, milk thistle, valerian root, curcumin and borage. The effectiveness of herbal and nutritional supplements in the treatment of OCD should be supported with more conclusive evidence.

\section{INTRODUCTION}

Obsessive-compulsive disorder (OCD) is a neuropsychiatric disorder that is characterised by obsessions and compulsions. OCD usually begins in childhood or adolescence and comorbid disorders such as mood, anxiety, psychotic and somatoform disorders are common in patients with OCD. ${ }^{1}$

Structural, neurochemical, genetic and immunological factors play a role in the aetiology and pathophysiology of OCD. ${ }^{2}$ Alterations in certain neurotransmitters are involved in OCD symptoms. Serotonin deficiency and the dysfunction in the availability of serotonin transporter (5-HTT) have been implicated in OCD symptomatology. ${ }^{3}$ In addition, elevated glutamate, glutamine and gamma aminobutyric acid (GABA) levels in the caudate nucleus ${ }^{4}$ and increased glutamate levels in the cerebrospinal fluid have been found in patients with OCD. ${ }^{5}$ Also, the glutamatergic ionotropic N-methyl D-aspartate (NMDA) receptor has been associated with OCD. ${ }^{6}$

The recommended treatments for OCD are cognitive-behavioural therapy using exposure and response prevention ${ }^{7}$ and/or pharmacotherapy with selective serotonin reuptake inhibitors (SSRI), the tricyclic antidepressant clomipramine, or serotonin noradrenaline reuptake inhibitors such as venlafaxine or duloxetine. ${ }^{89}$

Limited effectiveness and possible side effects of present treatments have lead to the search for alternative strategies. It is known that various nutritional deficiencies can be detected in patients with mental disorders. Therefore, nutritional supplements are thought to be effective in treatment. In this paper, use of nutritional and herbal supplements in the treatment of OCD will be reviewed.

\section{METHODS}

This review is focused on herbal and nutritional treatments for OCD. Therefore, PubMed (Medline), Cochrane and Google Scholar databases were searched using the terms 'Obsessive-Compulsive Disorder' OR 'OCD' in combination with 'herbal' OR 'plant' OR 'nutrition' OR 'nutraceuticals' OR ‘supplement' OR 'minerals' OR 'vitamin'. Papers written in English and conducted with humans were reviewed.

\section{RESULTS}

\section{Vitamin D}

Vitamin D has important functions in immunity modulation, inflammatory response and antioxidant processes. ${ }^{10}$ It is also essential for normal brain development and functioning, and plays key roles nervous system processes such as neurotransmission, neuroprotection, proliferation and differentiation. ${ }^{11} 12$

Vitamin D is synthesised in the epidermis as vitamin $\mathrm{D}_{3}$ (cholecalciferol) and then it is converted to $25-\mathrm{OH} \mathrm{D}_{3}$ in the liver by hydroxylation. After rehydroxylation in the kidney, 25-OH $\mathrm{D}_{3}$ becomes 1,25-dihydroxy-vitamin $\mathrm{D}_{3}$, the active form of vitamin $\mathrm{D} .{ }^{11}$ 
Previous studies have demonstrated that vitamin D deficiency is associated with numerous neuropsychiatric diseases that include autism, major depressive disorder, schizophrenia and OCD. ${ }^{13-15}$ There are several possible relationships between vitamin $\mathrm{D}$ and $\mathrm{OCD}$ pathophysiology. One of these is the association between the active form of vitamin $\mathrm{D}_{3}$ (1,25-dihydroxy-vitamin $\mathrm{D}_{3}$ ) and tyrosine/tryptophan hydroxylase. While tyrosine hydroxylase is the rate-limiting enzyme in dopamine, epinephrine and norepinephrine synthesis, tryptophan hydroxylase is the rate-limiting enzyme in serotonin synthesis. Levels of these two enzymes are regulated by 1,25-dihydroxy-vitamin $\mathrm{D}_{3} .{ }^{16} 17$ Therefore, vitamin $\mathrm{D}$ deficiency may contribute to OCD aetiology by affecting the pathway of serotonin and catecholamines synthesis.

The other relationship between vitamin $\mathrm{D}$ and $\mathrm{OCD}$ has to do with the neuroprotective effect of vitamin D. In some studies, the role of free radicals, especially increased levels of nitric oxide, is shown in OCD. ${ }^{18}$ Vitamin D has antioxidant effects and inhibits an essential enzyme (inducible nitric oxide synthase) for nitric oxide synthesis. ${ }^{19}$ Thus, vitamin $\mathrm{D}$ deficiency may play a role in $\mathrm{OCD}$ by causing the deterioration of neuroprotection.

In the literature, all available papers on OCD and vitamin $\mathrm{D}$ are studied with child and adolescent patients. There is no adult study on this topic. Esnafoğlu and Yaman have compared vitamin $\mathrm{D}$, vitamin $\mathrm{B}_{12}$, homocysteine and folic acid levels between 52 patients with OCD and 30 healthy controls. They found that there was a negative correlation between severity of OCD and the level of vitamin $\mathrm{D}$ and also vitamin $\mathrm{D}$ levels were lower in patients with OCD. ${ }^{20}$ On the other hand, Yazici et al showed no significant difference in vitamin $\mathrm{D}$, calcium, phosphate and alkaline phosphatase levels between patients with OCD and healthy controls. But the level of vitamin $\mathrm{D}$ was negatively correlated with symptom severity in patients with OCD. ${ }^{21}$ This study has compared 60 patients with OCD and 60 healthy controls. Similarly, Celik et al found lower vitamin $\mathrm{D}$ levels in paediatric autoimmune neuropsychiatric disorders were associated with streptococcal infection (PANDAS)- in patients with OCD $(n=33)$ compared to healthy controls $(n=20)$, but the difference was not statistically significant. ${ }^{22}$ PANDAS is a neuropsychiatric disorder that OCD symptoms manifest in following streptococcal infections. There may be a relationship between vitamin $\mathrm{D}$ levels and increasing oxidative stress due to recurrent infections in patients with PANDAS. ${ }^{22}$

Vitamin D levels can be influenced by latitude and season, due to sunlight. Celik et al and Yazici et al have stated the time interval of blood samples taken. But in the study of Esnafoğlu and Yaman, it is not clear.

\section{Vitamin $\mathrm{B}_{12}$, folic acid and homocysteine}

Vitamin $B_{12}$, folic acid and homocysteine play an important role in carbon transfer metabolism that maintains the methylation of proteins, neural membrane phospholipids and neurotransmitters such as serotonin and other monoamines. Thus, neurotransmitter levels may decrease due to deficiency of vitamin $\mathrm{B}_{12}$ and folic acid. ${ }^{23}$ Increased plasma homocysteine levels are accepted as a sensitive marker of folic acid and vitamin $\mathrm{B}_{12}$ deficiency. ${ }^{24}$ Increased homocysteine levels may cause DNA damage, mitochondrial dysfunction, activation of apoptotic signals and increased oxidative stress. ${ }^{25}$ All these findings suggest that vitamin $\mathrm{B}_{12}$, folic acid and homocysteine may be related with the aetiology of OCD.

In the literature, there are case reports of patients with OCD having vitamin $B_{12}$ deficiency. ${ }^{26}{ }^{27}$ Also, some studies have investigated the association between OCD and vitamin $\mathrm{B}_{12}$, folic acid, and homocysteine levels both in adult and child-adolescent patients. Hermesh et al have compared 30 patients with OCD, 30 patients with chronic schizophrenia and 30 healthy controls. They have reported that vitamin $B_{12}$ deficiency was more frequent in patients with OCD compared with controls, but there was no significant difference between vitamin $B_{12}$ and folate levels among the three groups. ${ }^{28}$ Atmaca et al found lower folate and higher homocysteine levels in patients with OCD $(n=23)$ compared with controls $(n=23)$ and those levels were significantly correlated with the symptom severity of OCD. ${ }^{29}$ Türksoy et al showed that vitamin $\mathrm{B}_{12}$ deficiency was significantly higher in patients with OCD $(n=35)$ compared with control $(n=22) \cdot{ }^{30}$ But folate deficiency was not found in either group. Additionally, homocysteine levels were significantly higher in the OCD group, and highest in the OCD group with major depressive disorder. Similarly, Esnafoğlu and Yaman found lower vitamin $\mathrm{B}_{12}$ and higher homocysteine levels in the group of children and adolescents with OCD compared with healthy controls. However there was no significant difference in the folic acid levels of both groups. ${ }^{20}$ A doubleblind, 12-weeks study was conducted in 36 patients with OCD who were randomly assigned to folic acid+fluoxetine or placebo+fluoxetine group. They have reported no significant difference in Yale-Brown Obsessive Compulsive Scale (Y-BOCS) scores between folic acid and placebo groups. Also, all baseline folate levels of patients with OCD were not lower than the normal range. ${ }^{31}$

Folate and vitamin $B_{12}$ levels might be influenced by dietary habits. So the results of studies can vary in samples from different societies.

\section{Trace elements}

Imbalances in trace elements may be associated with the pathophysiology of OCD. Selenium is an essential trace element that plays a role in the antioxidant properties of glutathione peroxidase.$^{32}$ Ozdemir et al found that serum selenium level was lower in patients with OCD $(n=28)$. They reported a positive correlation between plasma glutathione peroxidase activity and selenium concentration. ${ }^{33}$ In another study, 48 patients with OCD were compared with 48 healthy controls and found that serum zinc, iron and magnesium levels decreased in patients with OCD; however, manganese and calcium levels were increased. Also, they reported an imbalance in the trace elemental homeostasis and element-to-element inter-relationship 
pattern. ${ }^{34}$ In a pilot, randomised, double-blind, placebocontrolled study, patients with OCD $(n=30)$ who had taken an SSRI for at least 3 months were divided into two groups. While one group took $400 \mathrm{mg}$ selenium capsules plus SSRI, the other group took placebo plus SSRI. At the end of the 6 weeks, it was reported that there was a significant difference in Y-BOCS scores between the two groups. ${ }^{35}$ Selenium is a dietary element, so results of these studies could be affected by dietary habits.

Zinc is an antioxidant trace element that is required for many processes such as gene expression, protein synthesis and enzymatic catalysis. ${ }^{36}$ Zinc presents in the central nervous system, cerebral cortex, pineal gland and hippocampus, and modulates inhibitory and excitatory transmissions such as GABA and NMDA. ${ }^{37}$ In a randomised placebo-controlled clinical trial, one group received fluoxetine plus zinc, other group received fluoxetine plus placebo for 8 weeks. This study showed that the zinc group had a greater improvement compared with the placebo group. ${ }^{38}$

Because of the possible role of oxidation mechanisms in OCD pathogenesis, trace elements associated with antioxidant processes are thought to be useful in OCD treatment.

\section{$\mathrm{N}$-acetyl cysteine}

$\mathrm{N}$-acetyl cysteine (NAC) is a better source of cysteine rather than parenteral cysteine due to being less reactive, less toxic, more resistant to oxidation and more soluble in water. ${ }^{39}$ Some high-protein foods may be the source of cysteine but NAC should be taken as a supplement. NAC is well tolerated thus an oral dose of it can be increased up to $8000 \mathrm{mg} / \mathrm{d}$ without significant adverse effect. ${ }^{40}$

NAC, which is orally taken, is converted to cysteine in the liver and used for glutathione synthesis. ${ }^{40}$ Cysteine may cross the blood-brain barrier. So, cysteine prodrugs such as NAC inhibit the synaptic glutamate release by cysteine-glutamate exchange and may contribute to the treatment of psychiatric disorders. ${ }^{41}$ When the role of oxidative stress in the pathogenesis of OCD is considered, NAC that reduces oxidative stress and inflammation may be beneficial for OCD. ${ }^{42}$

In a case study of a patient with SSRI-refractory OCD, Lafleur et al showed that there was a significant improvement in OCD symptoms due to the NAC $(3000 \mathrm{mg} / \mathrm{d})$ augmentation of fluvoxamine. ${ }^{43}$ In contrast, a series of six case reports of patients with treatment-resistant severe OCD observed little efficacy of NAC $(3000 \mathrm{mg} / \mathrm{d})$ treatment. ${ }^{44} \mathrm{~A}$ randomised clinical trial assessing NAC treatment in OCD showed a significant improvement of symptoms in the SSRI plus NAC group $(2400 \mathrm{mg} / \mathrm{d})$ compared with SSRI plus placebo group. But patients' comorbidities have not been included in evaluations. ${ }^{45}$ Sarris $e t a t^{46}$ have conducted a randomised, double-blind, placebo-controlled clinical trial of NAC augmentation in patients with OCD who have been taking psychotropic drugs or adjunctive therapies. The NAC-treated group had more reduction in Y-BOCS score compared with the placebo group. The same authors have made a further analysis and reported that NAC is more effective in younger patients with a shorter diagnosis period of OCD. ${ }^{47}$ The other randomised double-blind placebocontrolled trial did not demonstrate a significant benefit of NAC in reducing OCD symptoms in patients with treatment-resistant OCD but NAC might have effects on reducing anxiety symptoms in these patients. ${ }^{48}$ In this study, patients were taking at least an SSRI. Paydary et $a l^{49}$ have compared NAC augmentation plus fluvoxamine treatment with placebo. There was no significant difference in Y-BOCS scores between the two groups, however NAC-treated patients accomplished remission more than the control group. Ghanizadeh et a $\tilde{p}^{0}$ performed a randomised, double-blind, placebo-controlled study that searched NAC augmentation of citalopram treatment in children and adolescents. Y-BOCS scores were significantly decreased in the NAC group.

\section{Glycine}

Glycine is an amino acid that is associated with cortical glutamatergic function. Glycine has potential to ameliorate OCD symptoms due to its agonist effect on NMDA receptors. ${ }^{51}$ High-protein foods such as meat, fish, beans and dairy products include glycine. A case report showed benefit of glycine in patients with OCD and body dysmorphic disorder but large amounts of glycine $(60 \mathrm{~g} / \mathrm{d})$ are required and unfortunately the large daily dose of glycine had side effects such as significant nausea. ${ }^{52}$ There is only a placebo-controlled, double-blind study on glycine augmentation in patients with OCD $(n=24)$. Dropout rates in this study were high due to adverse effects of glycine. Evaluable patients have showed near significant improvements in Y-BOCS scores. ${ }^{53}$

\section{Myoinositol}

Myoinositol (MI) is an endogenous isomer of glucose and has been used in the treatment of psychiatric disorders for a long time. High amounts of MI have been found in fruits, grains, nuts and beans. Also, MI is synthesised de novo from glucose-6-phosphate in the brain. A sustained supply of MI is essential for the synthesis of membrane phospholipids and for intracellular secondary messenger cycle. $^{54}$

It is suggested that MI may modulate the reuptake of serotonin and increase $5-\mathrm{HT}_{2}$ receptor density. Its therapeutic effects may be due to these mechanisms. ${ }^{55}$ There are few studies with small samples that investigate the efficacy of high-dose MI $(18 \mathrm{~g} / \mathrm{d})$ in OCD treatment. Fux $e t$ $a l$ and Carey et al reported positive data of MI supplementation in OCD treatment. ${ }^{56}$ The participants of these studies were not receiving concurrent SSRI treatment. In contrast, Fux et al and Seedat and Stein failed to find evidence for efficacy of MI in OCD treatment. ${ }^{5859}$ In these studies, MI has been used as augmentation for concurrent SSRI treatment. The existing clinical evidence suggests that MI may potentially be effective as monotherapy for OCD. 


\section{St John's wort (Hypericum perforatum)}

St John's wort (SJW) is derived from a plant and has been used for centuries as a traditional medicine to treat a wide range of disorders. The effectiveness of SJW has been mostly studied in depression and found to be equivalent to antidepressants. ${ }^{6061} \mathrm{SJW}$ contains flavonoid that has some anxiolytic effects. The neurobiological effects of SJW include monoamine reuptake inhibition, neuroendocrine modulation, increased sensitisation and binding to receptors (eg, 5-HT) ${ }^{61}$ These monoaminergic effects may have potential benefits on OCD symptoms.

Evidence for efficacy of SJW in OCD is based on only two studies. A 12-week open-label trial showed significant improvements with the treatment of SJW $(900 \mathrm{mg} / \mathrm{d})$ in patients with $\operatorname{OCD}(\mathrm{n}=12) .{ }^{62}$ A placebo-controlled trial with a much larger sample size $(\mathrm{n}=60)$ failed to show a significant difference between SJW (600-1800 mg/d) treatment group and placebo group. ${ }^{63}$

\section{Milk thistle (Silybum marianum)}

Silybum marianum (milk thistle) is a medicinal plant, which is grown in Mediterranean and Persian regions. ${ }^{64}$ It contains flavonoid complex silymarin, which has antiinflammatory, antioxidant, immune modulator, sedative and antidepressant effects. ${ }^{65}$ Also silymarin has been found to increase serotonin in the cortex and acts as a monoamine oxidase inhibitor. ${ }^{66}$

Results of the only randomised controlled trial $(n=35)$ of milk thistle for OCD treatment revealed no significant difference in treatment effects between milk thistle (600 $\mathrm{mg} / \mathrm{d}$ ) and fluoxetine. It is indicated that milk thistle has similar effects with fluoxetine in OCD symptoms and its positive effect starts in the fifth week without severe side effects. ${ }^{64}$

\section{Valerian root (Valeriana officinalis $L$ )}

Valerian is a perennial plant, which was used as a perfume in the 16th century. Valerian roots have aleuronic acid that is associated with the modulation of $\mathrm{GABA}_{\mathrm{A}}$ receptors. ${ }^{67}$ The other content of valerian roots is valepotriates, which is effective in treating the psychotic symptoms of severe anxiety. ${ }^{68}$ Valerian is most commonly used in insomnia and migraine treatment due to its sedative, pain reliever effects. There is only one double-blind placebo-controlled trial of valerian extract in OCD treatment $(n=31)$. They found that valerian extract was more effective in OCD treatment compared with placebo. Also, they observed the rapid onset of the effects of extract (28, 42, 56 days). Low incidence of impairment of libido with valerian extract was an important advantage of this treatment. ${ }^{69}$

\section{Curcumin}

Curcumin is an active constituent of turmeric. Both turmeric and curcumin are thought to strengthen the overall energy of the body, relieving gas, dispelling worms, improving digestion, regulating menstruation, dissolving gallstones and relieving arthritis. Curcumin is most commonly used to ameliorate pain associated with arthritis and other musculoskeletal disorders due to its anti-inflammatory effect. ${ }^{70}$ Potential pharmacodynamic benefits of curcumin in neuropsychiatric disorders are associated with the monoaminergic imbalances, hypothalamus-pituitary-adrenal axis disturbances, oxidative stress, mitochondrial disturbances and dysregulated inflammation. $^{71}$

Although there are no human studies that examine benefits of curcumin in OCD treatment, in an OCD animal model, rats were injected with the dopamineagonist quinpirole and compulsive checking was induced. After the oral curcumin administration for 35 days, compulsive checking and ritualistic behaviours were significantly reduced, and quinpirole-induced deteriorations were reversed. These effects of curcumin were comparable with paroxetine. ${ }^{72}$

\section{Borage (Echium amoenum)}

Borage is a traditional Persian plant, which has anxiolytic and sedative effects comparable to diazepam and also antidepressant effects. In only one study, borage extract $(n=24)$ has been compared with placebo $(n=20)$ in OCD treatment. While no significant difference was observed between the groups in the first week, a significant difference occurred at week 4 and week 6 . In addition, anxiety symptoms were significantly improved with the borage treatment over placebo. ${ }^{73}$

\section{CONCLUSION}

There are limited studies about herbal and nutritional supplements for OCD treatment in the literature. OCD and vitamin $\mathrm{D}$ association has been studied only in children and adolescents. Limited data show a negative correlation between OCD symptom severity and vitamin D. But these studies have been conducted in small samples and have some controversial points in methodology.

Vitamin $B_{12}$ and folate are thought to be effective in OCD treatment due to their associations with neurotransmitters. Depending on their antioxidant effect, zinc and selenium can be used in augmentation therapy for OCD. However, both trace elements and vitamin $\mathrm{B}_{12}$ /folate can be affected by diet. Therefore, dietary habits of participants have to be considered when designing studies on OCD treatment.

There are some studies and case reports that have shown improvement with NAC in OCD. However, these studies had small samples and participants who use SSRI or any psychotropic drug or psychotherapy. Data on the effect of glycine in OCD treatment are quietly restricted. On the other hand, maintaining treatment with glycine is very difficult due to its adverse effects. The existing limited clinical data suggest that MI may potentially be effective as monotherapy for OCD.

Some herbal medicines may provide a synergistic effect with pharmaceuticals. On the other hand, it should be noted that some herbal supplements should not 
be used with some drugs, for example, SJW with SSRIs due to potential serotonin syndrome. SJW, milk thistle, curcumin, valerian root and borage are herbal supplements that have been researched in OCD treatment. Despite the few studies on herbal supplements for OCD treatment, double-blind randomised controlled studies with standardised preparations of these herbals are needed. Although previous studies showed that some herbal and nutritional supplements might be potentially effective in OCD treatment, further double-blind randomised controlled longitudinal studies with structured measurement procedures in larger samples are needed.

Contributors All the authors contributed to the idea for the article, performing the literature search, manuscript writing and as guarantors.

Funding The authors have not declared a specific grant for this research from any funding agency in the public, commercial or not-for-profit sectors.

Competing interests None declared.

Patient consent for publication Not required.

Provenance and peer review Not commissioned; externally peer reviewed.

Open access This is an open access article distributed in accordance with the Creative Commons Attribution Non Commercial (CC BY-NC 4.0) license, which permits others to distribute, remix, adapt, build upon this work non-commercially, and license their derivative works on different terms, provided the original work is properly cited, appropriate credit is given, any changes made indicated, and the use is non-commercial. See: http://creativecommons.org/licenses/by-nc/4.0/.

ORCID iD

Canan Kuygun Karcı http://orcid.org/0000-0002-9355-9449

\section{REFERENCES}

1 Adam Y, Meinlschmidt G, Gloster AT, et al. Obsessive-compulsive disorder in the community: 12-month prevalence, comorbidity and impairment. Soc Psychiatry Psychiatr Epidemiol 2012;47:339-49.

2 Boileau B. A review of obsessive-compulsive disorder in children and adolescents. Dialogues Clin Neurosci 2011;13:401-11.

3 Goddard AW, Shekhar A, Whiteman AF, et al. Serotoninergic mechanisms in the treatment of obsessive-compulsive disorder. Drug Discov Today 2008;13:325-32.

4 Bolton J, Moore GJ, MacMillan S, et al. Case study: caudate glutamatergic changes with paroxetine persist after medication discontinuation in pediatric OCD. J Am Acad Child Adolesc Psychiatry 2001;40:903-6.

5 Chakrabarty K, Bhattacharyya S, Christopher R, et al. Glutamatergic dysfunction in OCD. Neuropsychopharmacology 2005;30:1735-40.

6 Arnold $P$, Rosenberg D, Mundo E, et al. Association of a glutamate (NMDA) subunit receptor gene (GRIN2B) with obsessive-compulsive disorder: a preliminary study. Psychopharmacology 2004;174:530-8.

7 Ougrin D. Efficacy of exposure versus cognitive therapy in anxiety disorders: systematic review and meta-analysis. BMC Psychiatry 2011;11:200.

8 Dell'Osso B, Nestadt G, Allen A, et al. Serotonin-Norepinephrine reuptake inhibitors in the treatment of obsessive-compulsive disorder. J Clin Psychiatry 2006;67:600-10.

9 Fineberg NA, Gale TM. Evidence-Based pharmacotherapy of obsessive-compulsive disorder. Int J Neuropsychopharmacol 1999;8:107-29.

10 Cannell JJ, Grant WB. What is the role of vitamin D in autism? Dermatoendocrinol 2013:5:199-204.10.4161/derm.24356

11 Eyles DW, Burne THJ, McGrath JJ. Vitamin D, effects on brain development, adult brain function and the links between low levels of vitamin D and neuropsychiatric disease. Front Neuroendocrinol 2013;34:47-64

12 Holick MF. Vitamin D and brain health: the need for vitamin D supplementation and sensible sun exposure. J Intern Med 2015;277:90-3.

13 Chiang M, Natarajan R, Fan X. Vitamin D in schizophrenia: a clinical review. Evid Based Ment Health 2016;19:6-9.
14 Wang T, Shan L, Du L, et al. Serum concentration of 25-hydroxyvitamin $D$ in autism spectrum disorder: a systematic review and meta-analysis. Eur Child Adolesc Psychiatry 2016;25:341-50.

15 Parker GB, Brotchie H, Graham RK. Vitamin D and depression. J Affect Disord 2017;208:56-61.

16 Cui X, Pertile R, Liu P, et al. Vitamin D regulates tyrosine hydroxylase expression: $\mathrm{N}$-cadherin a possible mediator. Neuroscience 2015;304:90-100.

17 Kaneko I, Sabir MS, Dussik CM, et al. 1,25-Dihydroxyvitamin D regulates expression of the tryptophan hydroxylase 2 and leptin genes: implication for behavioral influences of vitamin D. Faseb $J$ 2015;29:4023-35.

18 Behl A, Swami G, Sircar SS, et al. Relationship of possible stressrelated biochemical markers to Oxidative/Antioxidative status in obsessive-compulsive disorder. Neuropsychobiology 2010;61:210-4.

19 Garcion E, Sindji L, Montero-Menei C, et al. Expression of inducible nitric oxide synthase during rat brain inflammation: regulation by 1,25-dihydroxyvitamin D3. Glia 1998;22:282-94.

20 Esnafoğlu E, Yaman E. Vitamin B12, folic acid, homocysteine and vitamin $D$ levels in children and adolescents with obsessive compulsive disorder. Psychiatry Res 2017;254:232-7.

21 Yazici KU, Yazici P I, Ustundag B. Vitamin D levels in children and adolescents with obsessive compulsive disorder. Nord $\mathrm{J}$ psychiatry 2017:1-6.

22 Celik G, Tas D, Tahiroglu A, et al. Vitamin D deficiency in Obsessive-Compulsive disorder patients with pediatric autoimmune neuropsychiatric disorders associated with streptococcal infections: a case control study. Arch Neuropsychiatr 2016;53:33-7.

23 Bottiglieri T. Homocysteine and folate metabolism in depression. Prog Neuropsychopharmacol Biol Psychiatry 2005;29:1103-12.

24 Folstein M, Liu T, Peter I, et al. The homocysteine hypothesis of depression. AJP 2007;164:861-7.

25 COŞAR A, İPÇIOĞLU OM, ÖZCAN Ömer, et al. Folate and homocysteine metabolisms and their roles in the biochemical basis of neuropsychiatry. Turk J Med Sci 2014;44:1-9.

26 Sharma V, Biswas D. Cobalamin deficiency presenting as obsessive compulsive disorder: case report. Gen Hosp Psychiatry 2012;34:578. e7-578.e8.

27 Valizadeh N, Valizadeh M. Obsessive compulsive disorder as early manifestation of B12 deficiency. Indian J Psychol Med 2011;33:203.

28 Hermesh H, Weizman A, Shahar A, et al. Vitamin B and folic acid serum levels in obsessive compulsive disorder. Acta Psychiatr Scand 1988;78:8-10.

29 Atmaca M, Tezcan E, Kuloglu M, et al. Serum folate and homocysteine levels in patients with obsessive-compulsive disorder. Psychiatry Clin Neurosci 2005;59:616-20.

30 Türksoy N, Bilici R, Yalçıner A, et al. Vitamin B12, folate, and homocysteine levels in patients with obsessive-compulsive disorder. Neuropsychiatr Dis Treat 2014;10:1671.

31 Ü T, Çorapçıoğlu A, Ş B, et al. Double blind controlled study of adding folic acid to fluoxetine in the treatment of OCD. Psychiatr Danub 2019:31:69-77.

32 Wołonciej M, Milewska E, Roszkowska-Jakimiec W. Trace elements as an activator of antioxidant enzymes. Postepy Hig Med Dosw 2016;70:1483-98.

33 Ozdemir E, Cetinkaya S, Ersan S, et al. Serum selenium and plasma malondialdehyde levels and antioxidant enzyme activities in patients with obsessive-compulsive disorder. Prog Neuropsychopharmacol Biol Psychiatry 2009;33:62-5.

34 Shohag H, Ullah A, Qusar S, et al. Alterations of serum zinc, copper, manganese, iron, calcium, and magnesium concentrations and the complexity of interelement relations in patients with obsessivecompulsive disorder. Biol Trace Elem Res 2012;148:275-80.

35 Sayyah mehdi, Andishmand M, Ganji R. Effect of selenium as an adjunctive therapy in patients with treatment-resistant obsessivecompulsive disorder: a pilot randomized double blind placebocontrolled clinical trial. Arch Psych Psych 2018;20:57-65.

36 Takeda A. Movement of zinc and its functional significance in the brain. Brain Res Rev 2000;34:137-48.

37 Peters S, Koh J, Choi D. Zinc selectively blocks the action of Nmethyl-D-aspartate on cortical neurons. Science 1987;236:589-93.

38 Sayyah M, Olapour A, Saeedabad Yshahhosseini, et al. Evaluation of oral zinc sulfate effect on obsessive-compulsive disorder: a randomized placebo-controlled clinical trial. Nutrition 2012;28:892-5.

39 Bonanomi L, Toxicology GA. Pharmacokinetics and metabolism of acetylcysteine. Eur J Respir Dis 1980;111:45-51.

40 Atkuri KR, Mantovani JJ, Herzenberg LA, et al. N-Acetylcysteine-a safe antidote for cysteine/glutathione deficiency. Curr Opin Pharmacol 2007;7:355-9. 
41 Camfield DA, Sarris J, Berk M. Nutraceuticals in the treatment of obsessive compulsive disorder (OCD): a review of mechanistic and clinical evidence. Prog Neuropsychopharmacol Biol Psychiatry 2011:35:887-95.

$42 \mathrm{Ng} \mathrm{F}$, Berk M, Dean O, et al. Oxidative stress in psychiatric disorders: evidence base and therapeutic implications. Int J Neuropsychopharm 2008:11:851-76.

43 Lafleur DL, Pittenger C, Kelmendi B, et al. N-Acetylcysteine augmentation in serotonin reuptake inhibitor refractory obsessivecompulsive disorder. Psychopharmacology 2006;184:254-6.

44 Van Ameringen M, Patterson B, Simpson W, et al. N-Acetylcysteine augmentation in treatment resistant obsessive compulsive disorder: a case series. J Obsessive Compuls Relat Disord 2013;2:48-52.

45 Afshar $\mathrm{H}$, Roohafza $\mathrm{H}$, Mohammad-Beigi $\mathrm{H}$, et al. N-Acetylcysteine add-ontreatment in refractory obsessive-compulsive disorder: arandomized, double-blind, placebo-controlled trial. J Clin Psychopharmacol 2012;32:797-803.

46 Sarris J, Oliver G, Camfield DA, et al. N-Acetyl cysteine (NAc) in the treatment of obsessive-compulsive disorder: a 16-Week, double-blind, randomised, placebo-controlled study. CNS Drugs 2015;29:801-9.

47 Sarris J, Oliver G, Camfield DA, et al. Participant characteristics as modifiers of response to $\mathrm{N}$-acetyl cysteine (NAc) in obsessivecompulsive disorder. Clin Psychol Sci 2016;4:1104-11.

48 Costa DLC, Diniz JB, Requena G, et al. Randomized, DoubleBlind, Placebo-Controlled Trial of $\mathrm{N}$-Acetylcysteine Augmentation for Treatment-Resistant Obsessive-Compulsive Disorder. J Clin Psychiatry 2017;78:e766-73.

49 Paydary K, Akamaloo A, Ahmadipour A, et al. N-Acetylcysteine augmentation therapy for moderate-to-severe obsessive-compulsive disorder: randomized, double-blind, placebo-controlled trial. J Clin Pharm Ther 2016;41:214-9.

50 Ghanizadeh A, Mohammadi MR, Bahraini S, et al. Efficacy of Nacetylcysteine augmentation on obsessive compulsive disorder: a multicenter randomized double blind placebo controlled clinical trial. Iran J Psychiatry 2017:12:134.

51 Singer HS, Morris C, Grados M. Glutamatergic modulatory therapy for Tourette syndrome. Med Hypotheses 2010;74:862-7.

52 Cleveland WL, DeLaPaz RL, Fawwaz RA, et al. High-Dose glycine treatment of refractory obsessive-compulsive disorder and body dysmorphic disorder in a 5-year period. Neural Plast 2009;768398.

53 Greenberg WM, Benedict MM, Doerfer J, et al. Adjunctive glycine in the treatment of obsessive-compulsive disorder in adults. J Psychiatr Res 2009;43:664-70.

$54 \mathrm{Kim} \mathrm{H}$, McGrath BM, Silverstone PH. A review of the possible relevance of inositol and the phosphatidylinositol second messenger system (PI-cycle) to psychiatric disorders-focus on magnetic resonance spectroscopy (MRS) studies. Hum Psychopharmacol 2005;20:309-26.

55 Harvey BH, Brink CB, Seedat S, et al. Defining the neuromolecular action of myo-inositol: application to obsessive-com- pulsive disorder. Prog NeuroPsychopharmacol Biol Psychiatry 2002;26:21-32.

56 Fux M, Levine J, Aviv A, et al. Inositol treatment of obsessivecompulsive disorder. Am J Psychiatry 1996;153:1219-21.

57 Carey PD, Warwick J, Harvey BH, et al. Single photon emission computed tomography (SPECT) in Obsessive-Compulsive disorder before and after treatment with inositol. Metab Brain Dis 2004:19:125-34.

58 Fux M, Benjamin J, Belmaker RH. Inositol versus placebo augmentation of serotonin reuptake inhibitors in the treatment of obsessive-compulsive disorder: a double-blind cross-over study. Int J Neuropsychopharm 1999;2:193-5.

59 Seedat S, Stein DJ. Inositol augmentation of serotonin reuptake inhibitors in treatment-refractory obsessive ??? compulsive disorder: an open trial. Int Clin Psychopharmacol 1999;14:353-6.

60 Rahimi R, Nikfar S, Abdollahi M. Efficacy and tolerability of Hypericum perforatum in major depressive disorder in comparison with selective serotonin reuptake inhibitors: a meta-analysis. Prog Neuropsychopharmacol Biol Psychiatry 2009;33:118-27.

61 Sarris J, Kavanagh DJ, Kava KDJ. Kava and St. John's wort: current evidence for use in mood and anxiety disorders. J Altern Complement Med 2009;15:827-36.

62 Taylor LH, Kobak KA. An open-label trial of St. John's wort (Hypericum perforatum) in obsessive-compulsive disorder. J Clin Psychiatry 2000;61:575-8.

63 Kobak KA, Taylor LVH, Bystritsky A, et al. St John??s wort versus placebo in obsessive???compulsive disorder: results from a doubleblind study. Int Clin Psychopharmacol 2005;20:299-304.

64 Sayyah M, Boostani H, Pakseresht S, et al. Comparison of Silybum marianum (L.) Gaertn. with fluoxetine in the treatment of obsessivecompulsive disorder. Prog Neuropsychopharmacol Biol Psychiatry 2010;34:362-5.

65 Katiyar SK. Silymarin and skin cancer prevention: anti-inflammatory, antioxidant and immunomodulatory effects (review). Int $J$ Oncol 2005;26:169-76.

66 Mazzio E, Harris N, Soliman K. Food constituents attenuate monoamine oxidase activity and peroxide levels in C6 astrocyte cells. Planta Med 1998;64:603-6.

67 Khom S, Baburin I, Timin E, et al. Valerenic acid potentiates and inhibits GABAA receptors: molecular mechanism and subunit specificity. Neuropharmacology 2007;53:178-87.

68 Andreatini R, Sartori VA, Seabra MLV, et al. Effect of valepotriates (valerian extract) in generalized anxiety disorder: a randomized placebo-controlled pilot study. Phytother Res 2002;16:650-4.

69 Pakseresht S, Boostani H, Sayyah M. Extract of valerian root (Valeriana officinalis L.) vs. placebo in treatment of obsessivecompulsive disorder: a randomized double-blind study. $J$ Complement Integr Med 2011;8.

70 Daily JW, Yang M, Park S. Efficacy of turmeric extracts and curcumin for alleviating the symptoms of joint arthritis: a systematic review and meta-analysis of randomized clinical trials. J Med Food 2016;19:717-29.

71 Lopresti AL, Hood SD, Drummond PD. Multiple antidepressant potential modes of action of curcumin: a review of its anti-inflammatory, monoaminergic, antioxidant, immunemodulating and neuroprotective effects. J Psychopharmacol 2012;26:1512-24.

72 Chimakurthy J, Murthy TE. Effect of curcumin on quinpirole induced compulsive checking: an approach to determine the predic- tive and construct validity of the model. N Am J Med Sci 2010;2:81-6.

73 Sayyah M, Boostani H, Pakseresht S, et al. Efficacy of aqueous extract of Echium amoenum in treatment of obsessivecompulsive disorder. Prog Neuropsychopharmacol Biol Psychiatry 2009;33:1513-6.

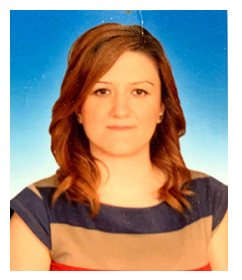

Dr. Canan Kuygun Karci graduated from Erciyes University Medical Faculty in 2006 and became the specialist of child and adolescent psychiatry in 2013 from Mersin University Medical Faculty. She works at Dr. Ekrem Tok Psychiatry Hospital, Child and Adolescent Psychiatry Department as specialist since 2015. Her research interests include child and adolescent psychiatry, child abuse, PANDAS. 